Article

\title{
Performances of Different Metabolic Lactobacillus Groups During the Fermentation of Pizza Doughs Processed from Semolina
}

\author{
Raimondo Gaglio ${ }^{1}$, Antonio Alfonzo ${ }^{1, *}$, Noemi Polizzotto ${ }^{1}$, Onofrio Corona ${ }^{1}$, \\ Nicola Francesca ${ }^{1}$, Giuseppe Russo ${ }^{2}$ (D) , Giancarlo Moschetti ${ }^{1}$ and Luca Settanni ${ }^{1}$ \\ 1 Dipartimento Scienze Agrarie e Forestali, Università degli Studi di Palermo, Viale delle Scienze 4, \\ 90128 Palermo, Italy; raimondo.gaglio@unipa.it (R.G.); noemipoli@hotmail.it (N.P.); \\ onofrio.corona@unipa.it (O.C.); nicola.francesca@unipa.it (N.F.); \\ giancarlo.moschetti@unipa.it (G.M.); luca.settanni@unipa.it (L.S.) \\ 2 Consorzio di Ricerca “Gian Pietro Ballatore”, Z.I. Dittaino s.n.c., 90040 Assoro (Enna), Italy; \\ giusepperusso@ilgranoduro.it \\ * Correspondence: antonio.alfonzo@unipa.it
}

Received: 22 June 2018; Accepted: 31 July 2018; Published: 3 August 2018

\begin{abstract}
The main hypothesis of this work is that facultative and obligate heterofermentative Lactobacillus species can differently impact the final characteristics of pizza. The objective was to evaluate separately the behaviors of the obligate heterofermentative species (OHS), such as Lactobacillus sanfranciscensis, Lactobacillus brevis, and Lactobacillus rossiae, and the facultative heterofermentative species (FHS), including Lactobacillus plantarum, and Lactobacillus curvatus, in the sourdoughs to be used for pizza production. The production of the experimental pizzas was carried out with semolina (Triticum turgidum L. ssp. durum). The acidification process-which was followed by $\mathrm{pH}$, total titratable acidity (TTA), and lactic acid bacteria (LAB) development-indicated for all of the experimental trials that the kinetics is comparable to those of the controls. The fermentation quotient of the FHS trial was particularly higher than that of the other trials, including the control production performed with a sourdough inoculum used in an artisanal bakery. The dominance of the added strains indicated the clear persistence of L. sanfranciscensis PON100336, L. brevis 200571, and L. plantarum PON100148 in the obligate-facultative heterofermentative species (OFHS) trial. The pizzas were baked without seasoning in order to investigate weight loss, color, morphology, and a generation of volatile organic compounds (VOCs). The data showed the differences among trials regarding the inocula. Eight classes of VOCs were detected in the pizza samples with aldehydes, esters, alcohols, and acids as major compounds. The sensory attributes were significantly different for the judges and the pizzas. The multivariate statistical approach found marked differences among the trials. The results indicated that the application of mixed cultures of the facultative heterofermentative species of Lactobacillus determined high quality pizzas.
\end{abstract}

Keywords: facultative heterofermentative species; lactic acid bacteria; obligate heterofermentative species; pizza; sourdough fermentation; shape descriptors; volatile organic compounds

\section{Introduction}

The production of traditional pizza has remained almost unchanged for centuries and can be assumed as a simple process; the ingredients, mainly flour/semolina, water, salt, and a leavening agent are mixed together [1]. Traditionally, pizza is produced with sourdough technology [2], which is an ancient practice well appreciated in modern times for its numerous advantages over baker's yeast [3]. Sourdoughs are considered extremely complex ecosystems where lactic acid bacteria (LAB) represent 
the prevailing microbiota [4]. In particular, lactobacilli are highly adapted to the environmental conditions such as temperature, $\mathrm{pH}$, acidity, maltose as the most abundant fermentable carbohydrate and fructose as a potentially metabolic electron acceptor, $\mathrm{O}_{2}$, and antimicrobial compounds of this food matrix [5], and they represent the typical sourdough LAB [3]. The Lactobacillus associated with sourdough consist of obligate and facultative heterofermentative and obligate homofermentative species [6].

An extensive work carried out by Coppola et al. [7] on the leavened doughs for Neapolitan pizza revealed the presence of enterococci, lactobacilli, leuconostocs, and weissellas within the LAB community. However, the authors found the highest biodiversity in terms of species for the Lactobacillus genus. In particular, the survey evidenced a strong presence of facultative heterofermentative lactobacilli over the obligate heterofermentative species. The same authors [8] tested different combinations of Saccharomyces cerevisiae and LAB (including homo- and hetero-fermentative species), in order to evaluate their effect on the dough properties. The results showed that the fastest $\mathrm{pH}$ drop was registered in presence of Lactobacillus plantarum.

The species of LAB belonging to the heterofermentative group are particularly relevant during the fermentation of sourdoughs [9], especially when they are propagated traditionally [10], through the 6-phosphogluconate/phosphoketolase pathway, the heterofermentative LAB generate lactic acid, ethanol or acetic acid (the last compound in presence of external electron acceptors), and $\mathrm{CO}_{2}$ [11]. These $\mathrm{LAB}$ species possess a constitutive phosphoketolase and are able to ferment pentose carbohydrates without $\mathrm{CO}_{2}$ formation. The phosphoketolase of the facultative heterofermentative $\mathrm{LAB}$ is induced by the available pentoses [6], but in the presence of hexose carbohydrates, they perform glycolysis and produce only lactic acid. Thus, the facultative heterofermentative and obligate heterofermentative species determine the different proportions of lactic and acetic acid.

When sourdough technology is applied for bread production, the heterofermentative LABs are preferred [12], as they partly contribute to the leavening process [13]. However, it is not clear what the impact is of the different metabolic classes of LAB on the final characteristics of pizza as it is consumed, as seasoning and the different acid proportions might influence the final appreciation by consumers. For these reasons, the main objective of this work was to evaluate exclusively the influence of different populations of obligate and facultative heterofermentative LABs, without yeast addition on the microbiological and the chemico-physical properties of the sourdoughs and on the physical, chemical, and sensory characteristics of the resulting pizzas. In particular, the sourdoughs were developed upon a selected LAB mixture acidification; once the $\mathrm{pH}$, acidity, acid composition, and microbiological parameters were evaluated, they were processed into pizzas, which were characterized for the same parameters, but also subjected to the analysis of the volume, texture, color, morphological characteristics, emission of volatile compounds, and sensory attributes after baking.

\section{Materials and Methods}

\subsection{Raw Materials, Starter Strains, and Growth Conditions}

Commercial durum wheat (Triticum turgidum L. ssp. durum) semolina (Mulini Gaspare Salvia, Partinico, Italy) was used to carry out the pizza production.

The strains used for the pizza dough fermentation were all members of the Lactobacillus genus namely: L. sanfranciscensis PON 100336, L. brevis 200571, and L. rossiae PON 100500 among the obligate heterofermentative species, and L. plantarum PON 100148, L. graminis PON 100244, and L. curvatus PON 100490 among the facultative heterofermentative species. All of the strains belonged to the culture collection of the Department of Agricultural, Food, and Forestry Sciences, the University of Palermo (Italy). The strain of L. sanfranciscensis was first isolated from Sicilian semolina and characterized for its technological properties useful in sourdough fermentation [14], while the other strains had a fermented dough origin $[15,16]$. 
Lactobacillus brevis, L. rossiae, L. plantarum, and L. curvatus were reactivated in the modified-MRS (mMRS) broth [15], while L. sanfranciscensis and L. graminis in were reactivated in the sour dough bacteria (SDB) broth [17] overnight at $30{ }^{\circ} \mathrm{C}$.

\subsection{Inoculum Preparation and Sourdough Production}

Three multi-strain starter cultures were prepared, one with the obligate heterofermentative species (OHS), one with the facultative heterofermentative species (FHS), and one with all of the strains together (OFHS). Each strain was previously tested singly in other works [14-16,18]. The strains were prepared individually after centrifugation of the overnight cells at $5000 \times g$ for 5 min by washing twice and re-suspension in Ringer's solution (Oxoid) until reaching an optical density at $600 \mathrm{~nm}$ of ca. 1.00, which approximately corresponds to a concentration of about $10^{9} \mathrm{CFU} / \mathrm{mL}$ for lactobacilli [16]. The adaptation of the strains to the substrates occurred in sterile conditions; each single inoculum $(1 \%, v / v)$ was then propagated into a sterile semolina extract (SSE), prepared as described by Alfonzo et al. [19], and incubated at $30^{\circ} \mathrm{C}$ for $24 \mathrm{~h}$. The multi-strain inocula were obtained by the contemporary addition of the fermented SSE to the corresponding raw materials, and were mixed with water. The combination of the three inocula with semolina, determined the three experimental trials: OHS, FHS, and OFHS. A sourdough (F1), available at bakery level and microbiologically characterized in the literature [16], was used for the control (CTR) trial.

The initial doughs were prepared with a dough yield (weight of the dough/weight of the flour or semolina $\times 100$ ) of 160 . Each dough of $640 \mathrm{~g}$ was obtained by adding $240 \mathrm{~mL}$ of the triple-strain cell suspension $(6.4 \mathrm{~mL}$ of each inoculum and $220.8 \mathrm{~mL}$ of still mineral water [Nestlè Vera, San Giorgio in Bosco, Italia] mixed into a sterile glass flask) to $400 \mathrm{~g}$ of semolina, reaching a final cell density of about $10^{6} \mathrm{CFU} / \mathrm{g}$. The kneading was performed by the mechanical mixer of the SilverCrest Bread Maker SBB 850 A1 (Kompernass GMBH, Bochum, Germany) for 15 min. Each dough (D) was then transferred to $2 \mathrm{~kg}$ cylindrical glass jars (Vetreria di Borgonovo, Borgonovo, Italy) and incubated at $30^{\circ} \mathrm{C}$ for $21 \mathrm{~h}$ to obtain the sourdoughs. All of the sourdoughs, including the controls, $(200 \mathrm{~g})$ were refreshed as indicated by a local pizza chef with the addition of $125 \mathrm{~g}$ of semolina and $75 \mathrm{~mL}$ of water, mixed mechanically and incubated at $30{ }^{\circ} \mathrm{C}$ for $21 \mathrm{~h}$. After six consecutive refreshments (RI-RVI), finally, the sourdoughs were used for pizza dough (PD) fermentation, following a classical regional recipe as follows: $64 \mathrm{~g}$ of each sourdough was mixed individually with $360 \mathrm{~g}$ of semolina, $216 \mathrm{~mL}$ of water, and $7.2 \mathrm{~g}$ of salt, and incubated at $30{ }^{\circ} \mathrm{C}$ for $8 \mathrm{~h}$. All of the trials were carried out in duplicate after two weeks.

\subsection{Chemical Analyses of Sourdoughs}

The measurement of the $\mathrm{pH}$ was performed by the Lab pH Meter Model pH 50 (XS Instruments, Carpi, Italy) on $10 \mathrm{~g}$ sourdough samples. The monitoring of the acidification process also included the determination of the total titratable acidity (TTA) trough titratation with $0.1 \mathrm{~N} \mathrm{NaOH}$ of sourdoughs (10 g), after homogenization with distilled $\mathrm{H}_{2} \mathrm{O}(90 \mathrm{~mL})$ by means of the Sorvall Omni-Mixer (Dupont Instruments, Newtown, CT, USA) for $1 \mathrm{~min}$ at the highest speed. The samples were analyzed at T0 and at $2 \mathrm{~h}$-intervals for the first $8 \mathrm{~h}$, and then at $21 \mathrm{~h}$. These measurements were carried out in triplicate. The results of the TTA were expressed as $\mathrm{mL}$ of $\mathrm{NaOH} / 10 \mathrm{~g}$ of sourdough.

Lactic and acetic acids were determined by high performances liquid chromatography (HPLC), as reported by Alfonzo et al. [14]. The pizza dough samples were collected just after preparation $\left(\mathrm{T}_{0}\right)$ and at the end of fermentation $\left(\mathrm{T}_{21}\right)$, and were treated as reported above for the TTA measurements, and were analyzed as follows: $10 \mathrm{~mL}$ of each suspension was added with $5 \mathrm{~mL}$ of $1 \mathrm{mM} \mathrm{a} \mathrm{HClO}_{4}$ solution; the mixtures were centrifuged at $4000 \times \mathrm{g}$ for $15 \mathrm{~min}$ at $15^{\circ} \mathrm{C}$, and the supernatants were acidified to $\mathrm{pH} 3.0 \pm 0.1$ with $1 \mathrm{mM} \mathrm{HClO}_{4}$, and brought to the final volume of $25 \mathrm{~mL}$ with distilled $\mathrm{H}_{2} \mathrm{O}$; the solutions were left in ice for $30 \mathrm{~min}$ and filtered through $0.45 \mathrm{~mm}$ cellulose filters (Millipore). The data were acquired and processed with the PerkinElmer software specific to the HPLC instrument (TotalChrom Workstation 2008 rev. 6.3.2). The chemical determinations were carried out in triplicate. 
The molar ratio between the lactic and acetic acid concentration, referred to as the fermentation quotient (FQ), was also calculated for all of the pizza dough samples.

\subsection{Microbiological Analysis and Monitoring of the Added Strains}

The levels of the main microbial groups in the sourdoughs were estimated at $T_{0}, T_{8}$, and $T_{21}$. The pizza doughs were analysed at $\mathrm{T}_{0}$ and at the end of fermentation $\left(\mathrm{T}_{8}\right)$. Each sample (15 g) was homogenized in Ringer's solution (135 mL) (Sigma-Aldrich, Milan, Italy) by means of a stomacher (BagMixer ${ }^{\circledR} 400$; Interscience, Saint Nom, France). After the serial decimal dilution, the cell suspensions were analyzed by spread plating, on plate count agar (PCA) incubated at $30{ }^{\circ} \mathrm{C}$ for $72 \mathrm{~h}$ for total mesophilic count (TMC); SDB agar, added with cycloheximide (10 mg/mL) to avoid fungal growth, incubated at $30{ }^{\circ} \mathrm{C}$ for $48 \mathrm{~h}$ for LAB; and Wallerstein laboratory (WL) nutrient agar, added with chloramphenicol $(0.05 \mathrm{mg} / \mathrm{mL})$ to avoid bacterial growth, incubated at $28{ }^{\circ} \mathrm{C}$ for $72 \mathrm{~h}$ for total yeasts. All of the media and chemical components were purchased from Oxoid. The plate counts were performed in duplicate.

The dominance of the strains that were added in the three trials was verified only at the end of fermentation the $(21 \mathrm{~h})$ for the sourdoughs at the sixth refreshment and for the pizza doughs $(8 \mathrm{~h})$. The colonies developed from the highest dilutions of the cell suspensions plated on the SDB were randomly collected (at least three identical colonies) and, after purification by three successive sub-culturing on the same medium, treated with $\mathrm{KOH}(3 \%, w / v)$ to determine the Gram type and with $\mathrm{H}_{2} \mathrm{O}_{2}(5 \%, v / v)$ to evaluate the catalase activity [20]. The Gram-positive and catalase-negative cultures were analyzed using the randomly amplified polymorphic DNA (RAPD)-PCR technique, as reported in the literature [21]. The amplicons were separated by electrophoresis on $1.5 \%(w / v)$ agarose gels (Gibco BRL, Cergy Pontoise, France) using a GeneRuler 100 bp Plus DNA ladder (M Medical Srl, Milan, Italy) as molecular size markers. The polymorphic profiles of the LABs were visualized by UV trans-illumination, after staining with the SYBR ${ }^{\circledR}$ safe DNA gel stain (Molecular probes, Eugene, OR, USA) and acquired with the GelCompar II software version 6.5 (Applied-Maths, Saint-Marten-Latem, Belgium), which was also used to compare the resulting RAPD patterns to those of L. sanfranciscensis PON 100336, L. brevis 200571, L. rossiae PON 100500, L. plantarum PON 100148, L. graminis PON 100244, and L. curvatus PON 100490.

\subsection{Pizza Baking and Analysis}

After fermentation, the pizza doughs were passed through the sheeting machine Atlas mod. 150 (Marcato S.p.a., Campodarsego, Italy) to reach the thickness of $1.5 \mathrm{~mm}$ [22]. The discs of a $10 \mathrm{~cm}$ diameter were cut with a circular stainless steel molder with a final weight of approximately $20 \mathrm{~g}$. The pizza discs were baked in a PizzaCLUB oven (ITALKERO SRL, Modena, Italy) equipped with a refractory stone at a temperature of 380 (top heat) and $310{ }^{\circ} \mathrm{C}$ (bottom heat) for $2 \mathrm{~min}$.

The weight of the pizzas was evaluated after cooling at ambient temperature for $15 \mathrm{~min}$. The color was measured on five points of the upper and lower surface of two pizzas for each trial, by means of the Chroma Meter CR-400C colorimeter (Minolta, Osaka, Japan). The Hunter's scale L*, $\mathrm{a}^{*}$, and $\mathrm{b}^{*}$ parameters were determined. The upper and lower pizza surfaces were also scanned (Epson Perfection 4180 Photo, Seiko Epson Corp., Japan) with a 300 dpi of resolution, and the images (TIFF format) were subjected to analysis through the ImageJ software (National Institutes Health, Bethesda, MD, USA). Squares of $207 \times 207$ pixels (corresponding to areas of $15 \times 15 \mathrm{~mm}$ ) were cropped from each image and were converted to grey-level $(8 \mathrm{bit})$. In order to detect the particle information to get a detailed explanation of the overall pizza morphology, the Otsu's threshold algorithm was applied to obtain binary images. The parameters area (white area and average area of white cells) and shape descriptors (circularity, roundness, and solidity), reported by Ferreira and Rasband [23], were calculated for each pizza sample.

The volatile organic compounds (VOCs) emitted from the pizzas were analyzed by the solid phase micro-extraction (SPME) isolation technique on $5 \mathrm{~g}$ of sample. Each sample was added with $20 \mu \mathrm{L}$ 
of 1-heptanol solution ( $35 \mathrm{mg} / \mathrm{L}$ 1-heptanol in 20\% ethanol aqueous solution) as internal standard and was heated to $60{ }^{\circ} \mathrm{C}$ in a vial and the headspace was collected by a DBV Carboxen-PDMS fibers (Supelco, Bellefonte, PA) for $40 \mathrm{~min}$. The SPME fiber was inserted into the Finnegan TraceMS for GC/MS (Agilent 6890 Series GC system, Agilent 5973 Net Work Mass Selective Detector, Milan, Italy) equipped with a DB-WAX capillary column (Agilent Technologies, $30 \mathrm{~m}, 0.250 \mathrm{~mm}$ i.d., film thickness $0.25 \mu \mathrm{m}$, part $\left.\mathrm{n}^{\circ} 122-7032\right)$. The analyses were carried out following the methodology described by Corona (2010) and Alfonzo et al. [14], and the identification of the chemical compounds was performed as reported by Settanni et al. [18]. The semi-quantitative determination was carried out by the method of the internal standard and the contents of the volatile compounds were expressed as $\mu \mathrm{g} / \mathrm{kg}$ of pizza. All of the solvents and reagents were purchased from WWR International (Milan, Italy). All of the determinations were performed in triplicate.

\subsection{Sensory Analysis}

The evaluation of the sensory attributes of the pizzas was performed after the propagation of the doughs by an expert pizza chef in a local pizzeria (Frank's PIZZA, Carini, Italy), in order to achieve the real conditions of production. The mature doughs were then moved to a pizzeria (Le Grotte del Kemonia, Palermo, Italy), located at a distance of $70 \mathrm{~m}$ from the Department of Agricultural, Food, and Forestry Sciences for the last propagation and baking. Consumer relevant conditions were obtained by seasoning with chopped tomatoes and extra-virgin olive oil. The diameter of the seasoned pizzas was $30 \mathrm{~cm}$. After baking, performed in an artisanal convection oven equipped with refractory stones and heated with olive wood at a temperature of 480 (top heat) and $440{ }^{\circ} \mathrm{C}$ (bottom heat) for approximately $3 \mathrm{~min}$, each pizza was cut into triangular portions and transferred to the Laboratory of Food Preparations for tasting.

Fourteen judges, including seven women and seven men ranging from 22 to 63 years old, were trained for the pizza evaluation. The analysis of the experimental pizzas was performed following the ISO 6658 guidelines. The attributes evaluated for each of the samples were selected from those suggested by Comendador et al. [24], and were adapted from the bread evaluation [25], including the aspect (crust color, presence of bubbles, and uniformity of bubbles), the smell (odor intensity, yeast odor, and unpleasant odor of crust), the texture (resistance to tearing, and crispness and chewiness of crust), the taste of the crust (sweet, salty, acid, and bitter; taste persistency; aroma intensity; and yeast aroma), and the taste of central part (sweet, salty, acid, and bitter, and the taste persistency). Furthermore, the overall acceptability of the product was also evaluated. Each attribute was scored by means of a line corresponding to a visual scale, with dislike/low quality levels on the left and like/high quality levels of the right. The linear levels (in $\mathrm{cm}$ ) were measured starting from the lowest point (on the left) until the marks put by the tasters.

\subsection{Statistical Analyses}

The analysis of variance (ANOVA) test was applied to identify significant differences among the chemical, physical, technological, microbiological, and sensory data. The post-hoc Tukey's method was applied for a pairwise comparison in case of microbial counts, organic acids, characteristics of pizza, and sensory scores. A statistical significance was attributed to $p$ values of $p<0.05$.

In addition, an explorative multivariate approach was employed to investigate the relationships among the data obtained from the different trials. An agglomerative hierarchical clustering analysis (HCA) was carried out for grouping the experimental pizzas according to their similarity, measured by Euclidean distances; whereas the cluster aggregation was based on the Ward's method [26]. The principal component analysis (PCAn) was performed with all of the data from the sourdoughs and pizzas together. The Barlett's sphericity test $[27,28]$ was applied to verify the differences that were statistically significant among the data sets of the trials. In order to select the number of principal factors, the Kaiser criterion [29] was applied; the factors showing eigenvalues $>1.00$ were retained for analysis. 
The levels of VOCs were graphically reported as a heat map, a representation with the different color intensity (from yellow to red) reporting the relative values of the VOCs, ranging from the lowest (yellow) to the highest (red) concentration, using the auto-scaled data [30].

The software XLStat version 2014.5.03. (Addinsoft, New York, NY, USA) was used for all of the statistical analyses.

\section{Results and Discussion}

\subsection{Changes of Chemical Parameters}

The evolution of the $\mathrm{pH}$ of the initial doughs, sourdoughs, and pizza doughs for the three experimental and the control trials are reported in Figure 1. The most consistent $\mathrm{pH}$ drop for the doughs was recorder after $6 \mathrm{~h}$ of fermentation. Regarding the sourdough refreshments, the behavior was almost comparable within each trial. The final pizza doughs at the 8th $\mathrm{h}$ of fermentations' results were statistically different; however, there were no differences between the $\mathrm{pH}$ of the trials carried out with the solely OHS or FHS, for which the results were higher than those of control trial.

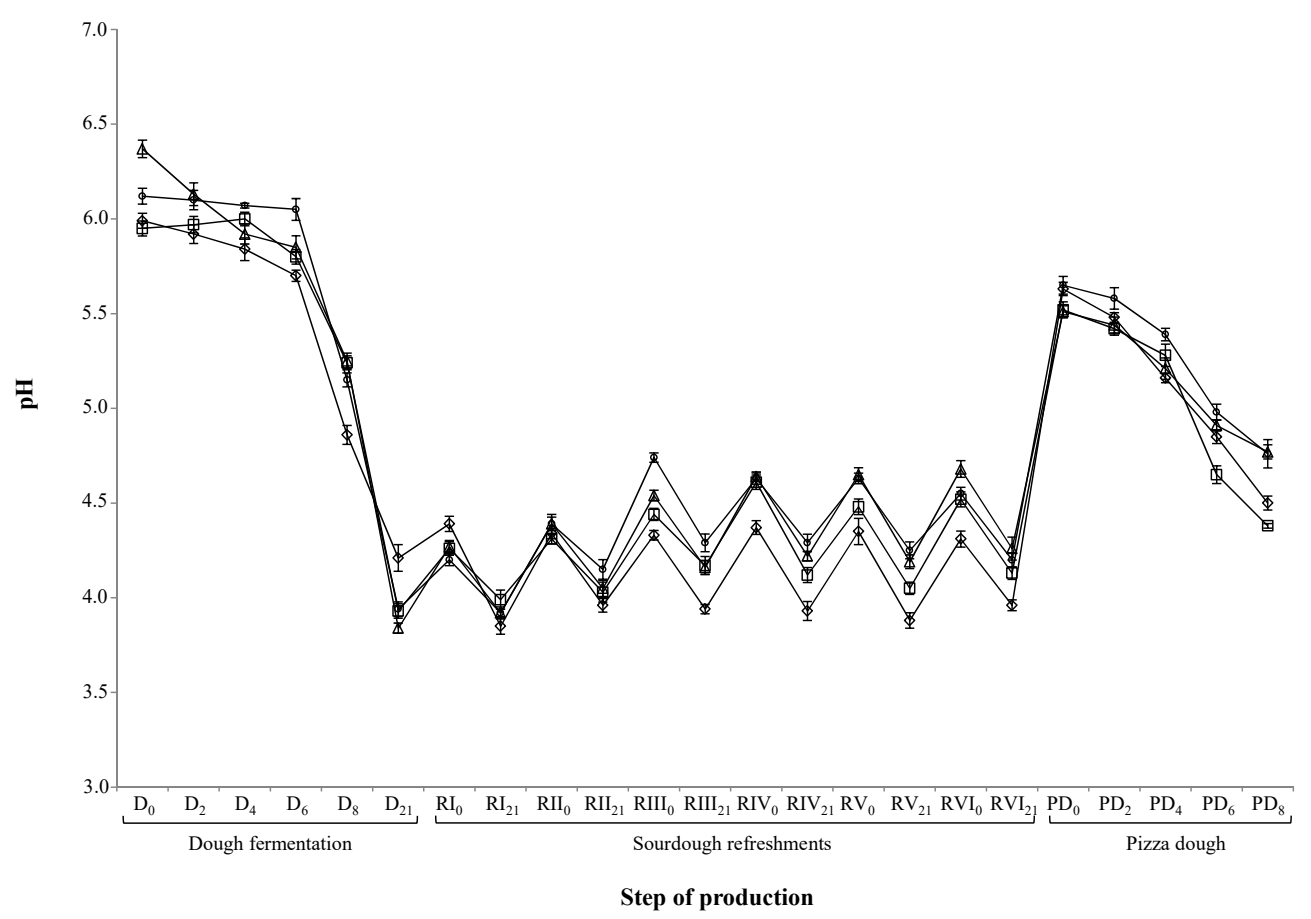

Figure 1. Evolution of $\mathrm{pH}$ during the dough preparation, sourdough propagation, and pizza dough production. Symbols: rhombus-control (CTR)-semolina; triangle-obligate heterofermentative species (OHS)-semolina; circle-facultative heterofermentative species (FHS)-semolina; square-obligate-facultative heterofermentative species (OFHS)-semolina.

The acidification of the eight trials was also followed by TTA (Figure 2). This parameter was correlated linearly with $\mathrm{pH}$, as a decrease of the $\mathrm{pH}$ corresponded to an increase of the acidity of the doughs, sourdoughs, and pizza doughs.

The concentration of the lactic and acetic acids was determined soon after the pizza dough preparation and after $8 \mathrm{~h}$ of fermentation (Table 1). The FQ resulting from the action of the different bacterial inocula was also determined, as the molar ratio between the lactic and acetic acid represents an important parameter affecting the aroma profile of the sourdoughs [3]. The lactic acid concentration was very low just after the ingredient mixing, but, after fermentation, it increased until $3.96 \mathrm{mg} / \mathrm{g}$ in the OFHS trial. The highest levels of acetic acid were registered after fermentation in the presence of the obligate heterofermentative LAB alone, or in combination with the facultative heterofermentative 
species. The dough that was started with the last species was characterized by a very high FQ, before and after fermentation. These results were determined by the very low levels of acetic acid rather than the lactic acid concentrations, which were comparable with those of the other trials. After $8 \mathrm{~h}$ of acidification, the pizza doughs produced with OHS and OFSH were characterized by FQs, in the range 1.5-4, which is considered to positively influence the aroma profile and the structure of the final sourdoughs [31]. The concentrations of the lactic and acetic acids and the corresponding FQs were comparable with the values registered for the sourdoughs propagated at an industrial level [12].

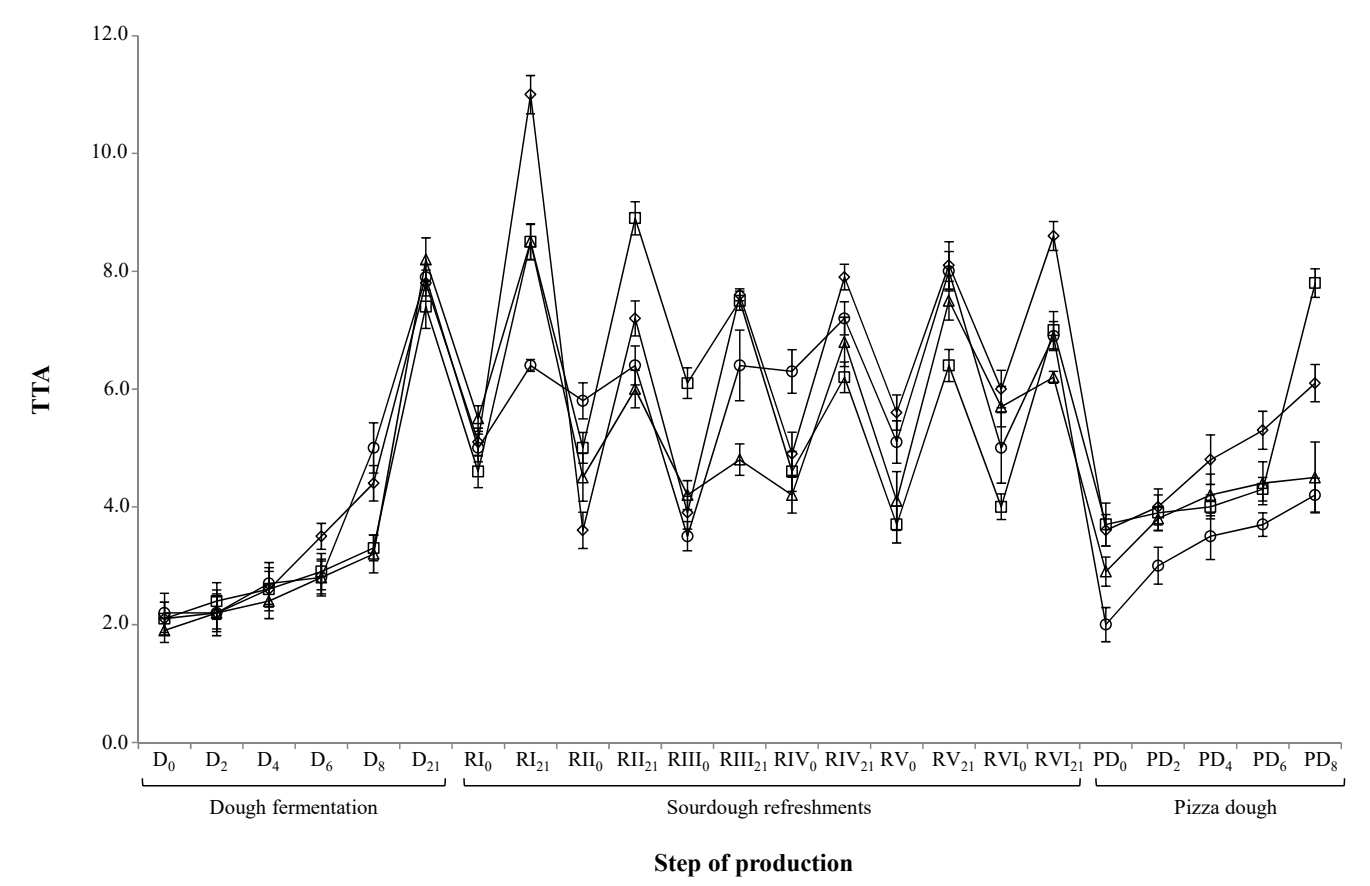

Figure 2. Evolution of total titratable acidity (TTA) during the dough preparation, sourdough propagation, and pizza dough production. Symbols: rhombus-CTR-semolina; triangle-OHS-semolina; circle-FHS-semolina; square-OFHS-semolina.

Table 1. Organic acids produced during pizza dough fermentation.

\begin{tabular}{cccc}
\hline Pizza Doughs & Lactic Acid $(\mathbf{m g} / \mathbf{g})$ & Acetic Acid $(\mathbf{m g} / \mathbf{g})$ & Fermentation Quotient \\
\hline $\mathrm{CTR} \mathrm{T}_{0}$ & $0.48 \pm 0.08^{\mathrm{b}}$ & $0.13 \pm 0.02^{\mathrm{d}}$ & 2.46 \\
$\mathrm{CTR} \mathrm{T}_{8}$ & $3.22 \pm 0.18^{\mathrm{a}}$ & $0.52 \pm 0.07^{\mathrm{bc}}$ & 4.13 \\
$\mathrm{OHS} \mathrm{T}_{0}$ & $0.81 \pm 0.21^{\mathrm{b}}$ & $0.20 \pm 0.06^{\mathrm{cd}}$ & 2.70 \\
$\mathrm{OHS} \mathrm{T}_{8}$ & $3.38 \pm 0.31^{\mathrm{a}}$ & $0.85 \pm 0.27^{\mathrm{ab}}$ & 2.65 \\
$\mathrm{FHS} \mathrm{T}_{0}$ & $0.91 \pm 0.28^{\mathrm{b}}$ & $0.07 \pm 0.02^{\mathrm{d}}$ & 8.67 \\
$\mathrm{FHS} \mathrm{T}_{8}$ & $3.91 \pm 0.38^{\mathrm{a}}$ & $0.16 \pm 0.05^{\mathrm{d}}$ & 16.29 \\
OFHS T $_{0}$ & $0.97 \pm 0.18^{\mathrm{b}}$ & $0.16 \pm 0.05^{\mathrm{d}}$ & 4.04 \\
OFHS T $_{8}$ & $3.96 \pm 0.45^{\mathrm{a}}$ & $0.89 \pm 0.17^{\mathrm{a}}$ & 2.97 \\
Statistical significance & $* * *$ & n.d. \\
\hline
\end{tabular}

Abbreviations: CTR-control; OHS—obligate heterofermentative species; FHS-facultative heterofermentative species; OFHS—obligate-facultative heterofermentative species; n.d.—not determined. The results indicate mean values \pm standard deviation (SD) of six measurements (carried out in triplicate for two independent fermentations). $p$ value: ${ }^{* * *}, p<0.001$.

\subsection{Microbial Evolution and Monitoring of the Added Cultures}

The levels of the microbial groups (LAB, TMC, and yeasts) investigated in the doughs, sourdoughs, and pizza doughs are reported in Figure 3. At the beginning of the process, LABs were detected at the highest levels in the doughs of the control trial. After $8 \mathrm{~h}$ of fermentation, the highest LAB levels 
were detected for the FHS trial and at $21 \mathrm{~h}$, as well as for the OFHS trial. At the end of the dough fermentation, the lowest LAB levels were registered for the control trial. Higher levels of LAB were also found in the experimental trials during the six sourdough refreshments, with almost 1 Log cycle of difference with the controls on average. This trend was also confirmed for the pizza doughs with levels above $9 \mathrm{Log}$ CFU/g, demonstrating the aptitude of the selected strains to develop at high numbers in the semolina doughs. In general, the numbers of the LAB registered during propagation were in the range commonly found in the mature sourdoughs produced in Sicily at an artisanal and industrial level [12,16,32]. Regarding the pizza doughs, the added LAB developed at higher levels than those reported in the literature for the artisanal productions [7].

The levels of TMC were almost 0.3-1.0 Log cycles lower than those of LAB, confirming previous studies [12,19] that showed a lower growth of this nutritionally exigent bacterial group on PCA, a substrate with a more limited availability of nutrients than SDB. Furthermore, the last medium is characterized by a $\mathrm{pH}$ of 5.6, which favors the growth of the sourdough LAB [19], while PCA has an almost neutral $\mathrm{pH}$, which represents a stressing growth factor for several LABs [33].

The yeasts started from an initial level in the range $4.35 \mathrm{Log}$ CFU/g in the control trial and the lower levels in the experimental trials. In particular, the doughs were characterized by levels of about 2.0 Log CUF/g. Unlike the control trial, the experimental trials were started only with LAB, thus, the yeast populations that were detected were those present in the raw material. The levels of yeasts from below 2.0 until 4.0 Log CFU/g have been reported for the semolina samples [19]. The numbers of yeast increased during fermentation. In general, they did not exceeded $10^{6} \mathrm{CFU} / \mathrm{g}$ in the control trials, while the levels higher than $10^{7} \mathrm{CFU} / \mathrm{g}$ were registered after fermentation during the refreshments and pizza dough development. In particular, this level was reached at the second refreshment for the experimental trials, with the exception of OFHS from the third-fourth refreshment. The increasing trend for the yeast levels observed by this study was similar to those reported by Corona et al. [12] for the experimental sourdoughs produced with different LAB strains. The ratio between the yeasts and the LAB was almost in the range, 1:100, for the majority of sourdough refreshments and pizza doughs, which is in agreement with those reported in the literature for the sourdoughs produced applying type I technology $[19,34,35]$, which is also applied for pizza production. However, Coppola et al. [7,8] reported bacteria/yeast ratios for the pizza doughs lower than those of the sourdoughs used in bread production.

In order to confirm the persistence of the starter strains during the refreshment of the sourdoughs until the pizza dough production, a RAPD analysis was applied on the Gram-positive and catalase negative isolates collected from the highest dilutions of the cell suspensions obtained from the sourdoughs at the sixth refreshment, and the pizza doughs at the end of fermentation and plated on SDB. The RAPD profiles of the LAB isolates were compared to those of the pure cultures of the added LAB (Figure 4). Recently, this strategy has been successfully applied to monitor the dominant fermenting LAB in different sourdoughs propagated at a laboratory and industrial level [12-19]. The direct comparison of the polymorphic profiles (results not shown) revealed that the sourdoughs and pizza doughs were almost dominated by all of the strains inoculated. In particular, the OHS trials showed similar levels of L. sanfranciscensis PON 100336 and L. brevis 200571, while L. rossiae PON 100500 was at 1 Log CFU/g lower. The FHS trial showed a clear dominance of L. plantarum PON 100148, followed by L. graminis PON 100244. Similar dominant levels of L. sanfranciscensis PON 100336, L. brevis 200571, and L. plantarum PON 100148 were detected in the OFHS trial. These species are known to dominate the traditional type I sourdough processes that are characterized by low incubation temperatures and a continuous back slopping [32]. Furthermore, besides L. sanfranciscensis, which is considered the key sourdough LAB [36,37], the species L. brevis and L. plantarum are ubiquitous to these environments [38]. None of the RAPD profiles of the selected added LAB were recognized among the isolates from the control sourdoughs and the pizza doughs, indicating that these trials were fermented by other strains. 

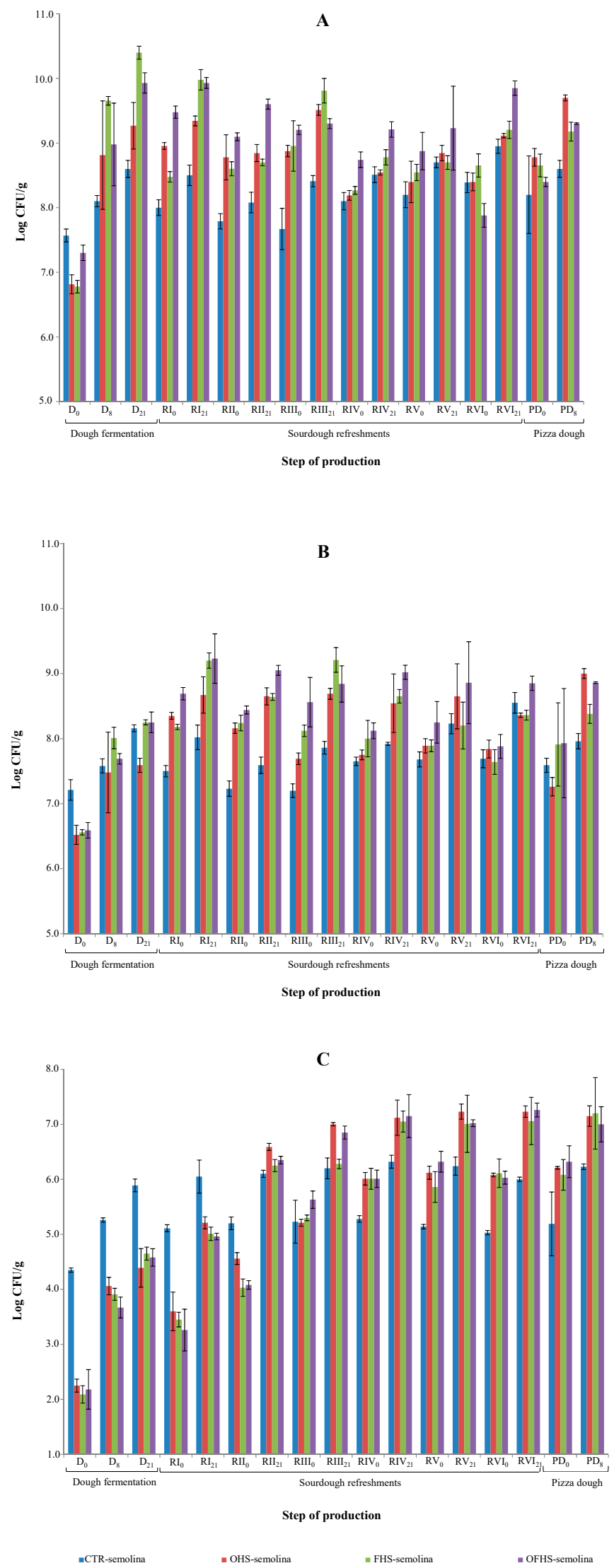

Figure 3. Levels of microorganisms during the dough preparation, sourdough propagation, and pizza dough production. (A) Lactic acid bacteria, (B) total mesophilic counts, and (C) yeasts. 


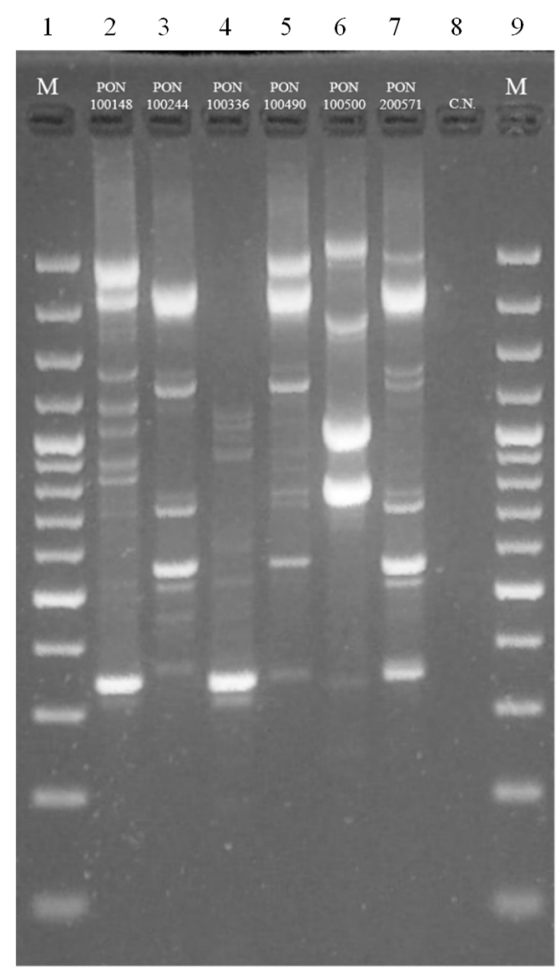

Figure 4. Randomly amplified polymorphic DNA (RAPD)-PCR profiles of LAB added as starter strains obtained with primer M13. Lanes: 1 and 9-GeneRuler 100 bp plus DNA ladder; 2-L. plantarum PON 100148; 3-L. graminis PON 100244; 4-L. sanfranciscensis PON 100336; 5-L. curvatus PON 100490; 6-L. rossiae PON 100500; 7-L. brevis 200571; 8-negative control.

\subsection{Characteristics after Baking}

After baking, the pizzas were cooled at room temperature and evaluated for quality characteristics, including weight, color, and morphology (Table 2). The weight loss among the trials were statistically different and the differences regarding inocula were consistent. The highest weight loss $(6.57 \mathrm{~g})$ was showed by the FHS trial.

The color parameters of the pizza samples showed different values. $L^{*}$ was higher when the pizzas were produced with an OHS inoculum, while the control trial showed the lowest value. The parameter $a^{*}$ did not follow a definite trend, because negative values were recorded for the OHS and FHS trials. As per the bread, these results confirm that the final color characteristics of the pizzas are influenced by the starter strains [18] and their interactions [12].

Regarding the information retrieved from the particles on the overall morphology of the pizzas, some differences were evidenced among the trials. As a general observation, the selected LAB determined higher white frequencies than the control sourdoughs in the pizzas. No statistical differences were observed for the three shape descriptors. In particular, the circularity showed values higher than 0.80 , showing a high regularity of particles, as a value of 1.0 indicates a perfect circle particle, while a value of 0.0 indicates an increasingly elongated shape [23]. Thus, the shape descriptors were not influenced by the bacterial inocula.

The pizza aroma is formed during kneading, fermentation, and baking; each process is affected by time and temperature. During fermentation, the secondary metabolic activities by the microorganisms lead to the release of a variety of VOCs. Subsequently, during baking, the precursor compounds previously formed lead to a number of volatile compounds, resulting from two non-enzymatic browning reactions, known as the Maillard reactions and caramelization, two phenomena rapidly observable at temperatures higher than $140{ }^{\circ} \mathrm{C}$, in addition to the oxidation of flour lipids [39,40]. Eight classes of volatile chemicals, including acids, alcohols, aldehydes, esters, furans, ketones, phenols, 
and terpenes, were detected in the pizza samples. As shown by the dendrogram resulting from the cluster analysis and the heat map (Figure 5), almost 45 VOCs were emitted from each pizza, showing a complexity of chemicals comparable to that generally reported for sourdough breads [41,42]. The OHS trial clustered with the control trial. These results showed a strong influence of the inoculums used in the dough fermentation for the generation of the VOCs in pizza. Aldehydes, esters, alcohols, and acids constituted the major classes of VOCs for all of the pizzas. D-limonene was the only terpene identified in the pizza obtained with semolina. Among the compounds found at the highest concentrations, acetic acid is due to the action of the heterofermentative LAB [11], and for this reason, it is poorly represented in the FHS trial. This compound is important in the sourdough product, because it is reported as a flavor enhancer [43]. The production of 3-methyl-1-butanol is responsible for the 'fermented' flavor in sourdough products [44], and is generally detected in the presence of the combination of a heterofermentative LAB [12]. Other alcohol compounds such as benzyl alcohol and 2-phenylethanol, are responsible for the "pleasant aromatic" and "flowery, yeast-like, and honey" [44], respectively, and are well represented in pizza. The aldehydes compounds that correlate positively with the aroma of the wheat bread, such [44] as nonanal (citrus, soapy), trans-2-nonenal (fatty, green, tallowy, paper, and cucumber-like), and phenylethanal (floral-green) were also detected. Furthermore, the presence of high concentrations of 5-methyl-2-furfural is common in these kinds of products, because it is a volatile marker of the baking process [45].

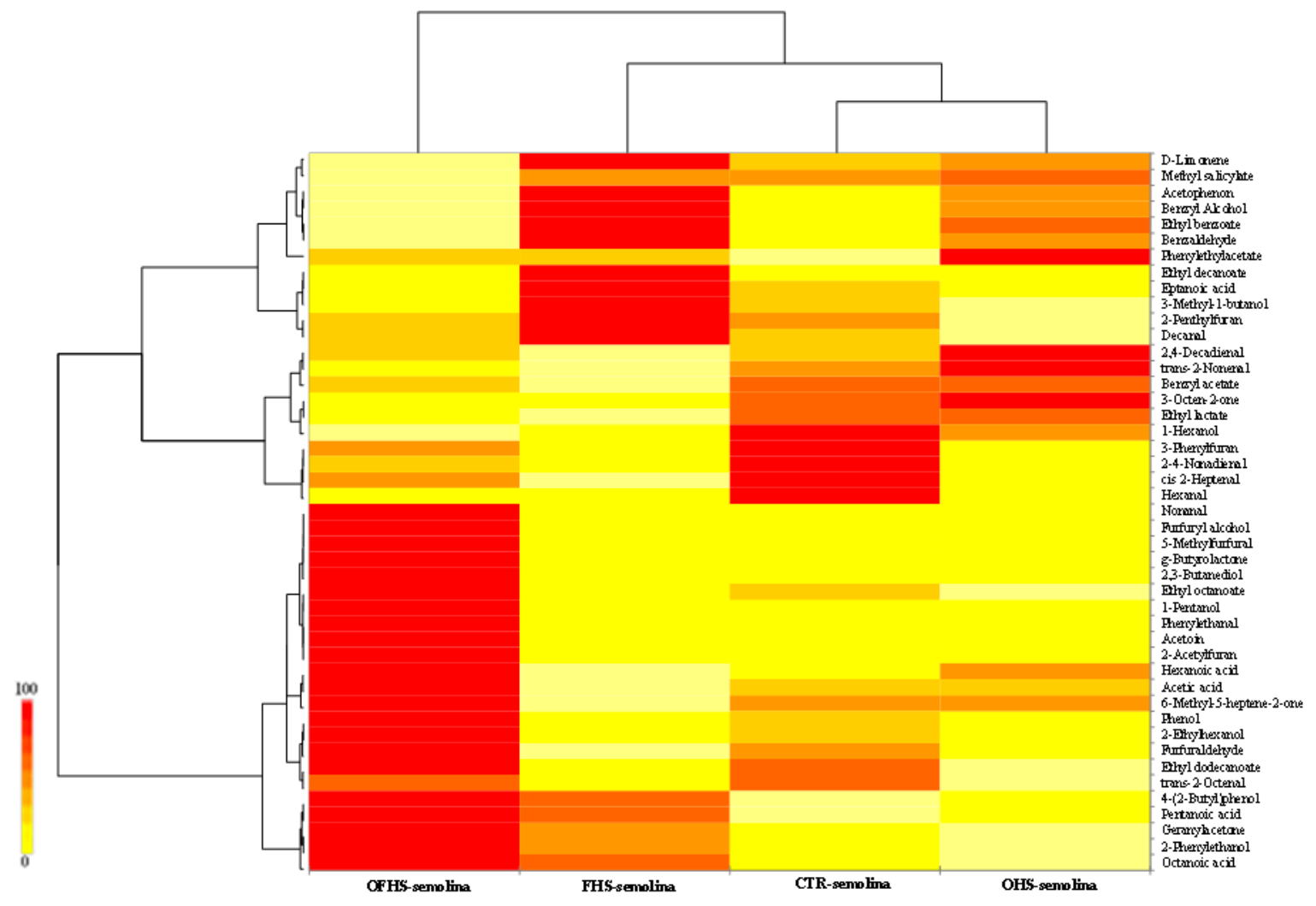

Figure 5. Distribution of the volatile organic compounds among the pizza samples from the different trials. The double hierarchical dendrogram is based on the values of the volatile organic compounds (VOCs). The heat map plot depicts the relative percentage of each compound within each pizza. Abbreviations: CTR — control; OHS_obligate heterofermentative lactobacilli; FHS—facultatively heterofermentative lactobacilli; OFHS—obligate heterofermentative lactobacilli. 
Table 2. Characteristics of unseasoned pizzas.

\begin{tabular}{|c|c|c|c|c|c|c|c|c|c|}
\hline \multirow{2}{*}{ Trial } & \multirow{2}{*}{ Weight Loss (g) } & \multicolumn{3}{|c|}{ Color } & \multirow{2}{*}{ White Area \% } & \multirow{2}{*}{$\begin{array}{c}\text { Average Area of } \\
\text { White Cells }\left(\mathrm{mm}^{2}\right)\end{array}$} & \multicolumn{3}{|c|}{ Shape Descriptors } \\
\hline & & $\mathbf{L}^{*}$ & $\mathbf{a}^{*}$ & $\mathbf{b}^{*}$ & & & Circularity & Roundness & Solidity \\
\hline CTR & $3.23 \pm 0.13^{b}$ & $40.64 \pm 0.84^{b}$ & $4.36 \pm 0.26^{\mathrm{a}}$ & $17.27 \pm 0.33^{b}$ & $33.63 \pm 0.31^{\mathrm{ab}}$ & $1.65 \pm 0.05^{\mathrm{a}}$ & $0.82 \pm 0.03^{a}$ & $0.74 \pm 0.05^{\mathrm{a}}$ & $0.86 \pm 0.04^{a}$ \\
\hline OHS & $4.51 \pm 0.17^{\mathrm{ab}}$ & $67.76 \pm 1.78^{a}$ & $-0.52 \pm 0.05^{b}$ & $21.42 \pm 0.35^{a}$ & $32.73 \pm 0.38^{b}$ & $1.24 \pm 0.03^{\mathrm{ab}}$ & $0.86 \pm 0.03^{a}$ & $0.74 \pm 0.06^{\mathrm{a}}$ & $0.91 \pm 0.02^{a}$ \\
\hline FHS & $6.57 \pm 0.17^{\mathrm{a}}$ & $64.56 \pm 1.76^{a}$ & $-0.54 \pm 0.03^{b}$ & $18.63 \pm 0.26^{b}$ & $37.35 \pm 0.32^{a}$ & $0.95 \pm 0.02^{b}$ & $0.84 \pm 0.06^{\mathrm{a}}$ & $0.72 \pm 0.05^{\mathrm{a}}$ & $0.89 \pm 0.04^{\mathrm{a}}$ \\
\hline OFHS & $5.67 \pm 0.14^{\mathrm{ab}}$ & $62.12 \pm 1.62^{a}$ & $3.80 \pm 0.04^{\mathrm{a}}$ & $23.46 \pm 0.42^{a}$ & $34.41 \pm 0.39^{\mathrm{ab}}$ & $0.57 \pm 0.01^{\mathrm{c}}$ & $0.90 \pm 0.02^{\mathrm{a}}$ & $0.79 \pm 0.08^{a}$ & $0.92 \pm 0.03^{a}$ \\
\hline $\begin{array}{l}\text { Statistical } \\
\text { significance }\end{array}$ & * & $* *$ & $* * *$ & $* *$ & $* *$ & $* * *$ & N.S. & N.S. & N.S. \\
\hline
\end{tabular}

Abbreviations: CTR—control; OHS—obligate heterofermentative lactobacilli; FHS—facultatively heterofermentative lactobacilli; OFHS—obligate heterofermentative lactobacilli. The results indicate the mean values \pm SD of six determinations (carried out in duplicate two independent productions). Data within a column followed by the same letter are not significantly different according to Tukey's test. $p$ value: ${ }^{*}, p<0.05 ; * *, p<0.01 ; * * *, p<0.001$; N.S. - not significant. 


\subsection{Evaluation of the Sensory Attributes of Pizzas}

Table 3 reports the results of the sensory tests conducted on the pizzas. All of the sensory attributes were significantly different for the judges and pizzas. The highest scores for crust color were registered in the OHS trial. The presence of bubbles was at highest in the control and FHS pizzas. No big differences were found for the odor intensity among the trials. Yeast and unpleasant odors were very low for all of the pizza samples. The highest values for the resistance to tearing were registered for the OFHS trial, while the crispness was registered for the OHS trial. In general, no consistent differences were found for the sweet and salty taste between the crust and center of pizzas, while the acidity was more appreciated in the central part as a result of the presence of tomato. The control trial results were characterized by a higher taste persistence than the other trials. Finally, higher scores for the overall assessment were showed by the control pizzas, which were comparable to those of the FHS trial. However, for the pizza sensory analysis, the impact of the organoleptic profiles of topping ingredients has to be taken into account [46].

Table 3. Sensory characteristics of experimental seasoned pizzas.

\begin{tabular}{|c|c|c|c|c|c|c|c|}
\hline \multirow{2}{*}{ Attributes } & \multicolumn{4}{|l|}{ Trials } & \multirow{2}{*}{ SEM } & \multicolumn{2}{|c|}{ Statistical Significance } \\
\hline & Control & OHS & FHS & OFHS & & Judges & Pizzas \\
\hline Crust color & $2.68^{\mathrm{b}}$ & $3.59^{\mathrm{a}}$ & $2.93^{b}$ & $2.51^{\mathrm{b}}$ & 0.22 & $* *$ & $* *$ \\
\hline Presence of bubbles & $5.21^{\mathrm{ab}}$ & $4.27^{\mathrm{c}}$ & $5.59^{\mathrm{a}}$ & $4.58^{\mathrm{bc}}$ & 0.29 & $* *$ & $* *$ \\
\hline Uniformity of bubbles & $3.56^{\mathrm{a}}$ & $3.03^{b}$ & $3.74^{\mathrm{a}}$ & $3.83^{\mathrm{a}}$ & 0.16 & $* *$ & $*$ \\
\hline Odor intensity & $3.24^{\mathrm{a}}$ & $3.25^{\mathrm{a}}$ & $2.69^{b}$ & $3.42^{\mathrm{a}}$ & 0.14 & $* *$ & $* *$ \\
\hline Yeast odor & $1.36^{\mathrm{b}}$ & $1.61^{\mathrm{a}}$ & $1.61^{\mathrm{a}}$ & $1.46^{\mathrm{ab}}$ & 0.07 & * & $* *$ \\
\hline Unpleasant odor & $1.25^{\mathrm{a}}$ & $1.29^{\mathrm{a}}$ & $1.19^{\mathrm{ab}}$ & $1.10^{\mathrm{b}}$ & 0.03 & * & * \\
\hline Resistance to tearing & $3.05^{b}$ & $3.63^{\mathrm{a}}$ & $3.01^{b}$ & $3.76^{\mathrm{a}}$ & 0.16 & $* *$ & $* *$ \\
\hline Crispness & $3.25^{b}$ & $4.69^{\mathrm{a}}$ & $3.58^{\mathrm{b}}$ & $3.50^{\mathrm{b}}$ & 0.31 & $* * *$ & * \\
\hline Chewiness & $3.69^{b}$ & $4.58^{\mathrm{a}}$ & $4.40^{\mathrm{a}}$ & $4.61^{\mathrm{a}}$ & 0.20 & $* *$ & $* *$ \\
\hline \multicolumn{8}{|l|}{ Taste of crust: } \\
\hline Sweet & $3.01^{b}$ & $2.90^{b}$ & $3.41^{\mathrm{a}}$ & $2.71^{b}$ & 0.14 & $* *$ & $* *$ \\
\hline Salty & $2.25^{\mathrm{b}}$ & $2.53^{a}$ & $2.03^{b}$ & $2.18^{b}$ & 0.11 & $* *$ & * \\
\hline Acid & $1.79^{a b}$ & $1.87^{\mathrm{a}}$ & $1.72^{b c}$ & $1.64^{\mathrm{c}}$ & 0.06 & $*$ & * \\
\hline Bitter & $1.52^{b}$ & $1.82^{\mathrm{a}}$ & $1.77^{\mathrm{a}}$ & $1.57^{\mathrm{b}}$ & 0.06 & * & $*$ \\
\hline Taste persistency & $5.20^{\mathrm{a}}$ & $3.86^{\mathrm{b}}$ & $3.73^{b}$ & $3.60^{b}$ & 0.34 & $* * *$ & $* * *$ \\
\hline Aroma intensity & $4.02^{\mathrm{a}}$ & $3.32^{b}$ & $3.34^{\mathrm{b}}$ & $3.20^{\mathrm{b}}$ & 0.11 & $* *$ & $* *$ \\
\hline Yeast aroma & $1.52^{\mathrm{b}}$ & $2.17^{\mathrm{a}}$ & $1.76^{\mathrm{ab}}$ & $2.15^{\mathrm{a}}$ & 0.13 & $* *$ & $* *$ \\
\hline \multicolumn{8}{|l|}{ Taste of center: } \\
\hline Sweet & $3.07^{\mathrm{b}}$ & $3.15^{\mathrm{ab}}$ & $3.33^{\mathrm{a}}$ & $2.97^{\mathrm{b}}$ & 0.07 & * & * \\
\hline Salty & $2.68^{a b}$ & $2.59^{\mathrm{bc}}$ & $2.77^{\mathrm{a}}$ & $2.51^{\mathrm{c}}$ & 0.08 & $* *$ & * \\
\hline Acid & $3.15^{\mathrm{a}}$ & $2.48^{b c}$ & $3.02^{a b}$ & $2.64^{c}$ & 0.15 & $* *$ & * \\
\hline Bitter & $1.65^{\mathrm{c}}$ & $1.89^{\mathrm{bc}}$ & $2.24^{\mathrm{a}}$ & $1.99^{\mathrm{ab}}$ & 0.11 & $* *$ & * \\
\hline Taste persistency & $3.96^{\mathrm{a}}$ & $3.71^{b}$ & $3.98^{\mathrm{a}}$ & $3.91^{\mathrm{a}}$ & 0.05 & * & * \\
\hline Overall assessment & $4.32^{\mathrm{a}}$ & $3.85^{b c}$ & $4.22^{a b}$ & $3.73^{c}$ & 0.13 & $* *$ & $* *$ \\
\hline
\end{tabular}

Abbreviations: OHS-obligate heterofermentative species; FHS-facultative heterofermentative species; OFHS - obligate-facultative heterofermentative species; SEM-standard error of means. $p$ value: ${ }^{*}, p<0.05$; ${ }^{* *}, p<0.01 ;{ }^{* * *}, p<0.001$. The results indicate the mean value. The data within a line followed by the same letter are not significantly different, according to Tukey's test.

\subsection{Multivariate Statistical Analysis}

The HCA grouped the eight trials into three main clusters, cutting the hierarchical tree diagram at about 25\% (Figure 6). The controls were clustered separately from the experimental trials. HCA represents an exploratory data analysis tool aimed at sorting the different objects into groups in a way that the degree of association between two objects is maximal if they belong to the same group, and minimal otherwise [47].

Regarding PCAn, the six eigenvalues were higher than 1 and the first four accounted for $86.68 \%$ of the total variability (data not showed). Factor 1 and Factor 2 together (Figure 7 ) explained $73.19 \%$ of 
the total variability and the 26 groups of variables were expressed as a linear combination of the first two factors. Figure 7A shows the correlation among the components of the PCAn and the variables considered, while the discrimination of the trials is visualized by the plot of scores (Figure 7B), showing the projection of the cases onto the planes as function of Factors 1 and 2 . The trials were significantly separated along Factor 1 on the basis of PCA, SDB, shape descriptors, phenols, L*, and crust taste. Other variables associated to values of weight loss, FQ, $\mathrm{pH}$, odor, and alcohols affected the distribution of the trials along Factor 2. The score plot clearly shows the far distance among the trials performed with the highest complexity of the selected LAB (OFHS) and the control trial. The last trial was very close to the FHS trial. From a practical perspective, the qualitative and quantitative distances of the individual samples obtained with different inocula provided an explanation of their behavior alone and in combination, and allowed for the interpretation of all of the data together [12].

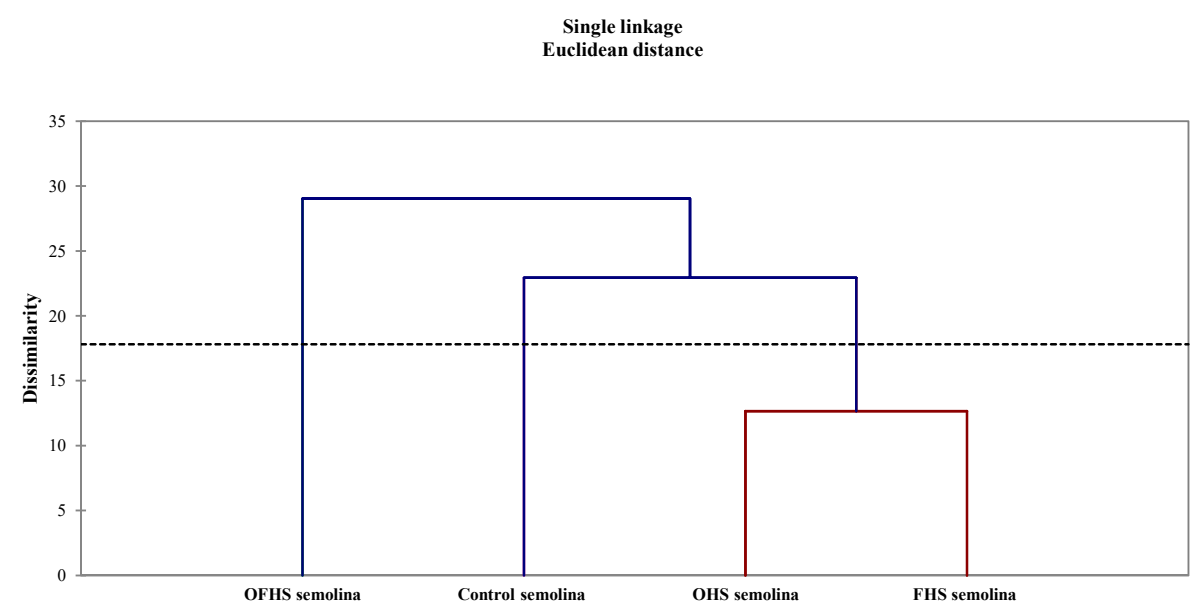

Figure 6. Dendrogram resulting from hierarchical cluster analysis on 26 variables determined on fermented pizza doughs, baked unseasoned pizzas, and final seasoned products. Abbreviations: OHS —obligate heterofermentative lactobacilli; FHS—facultatively heterofermentative lactobacilli; OFHS—obligate heterofermentative lactobacilli.

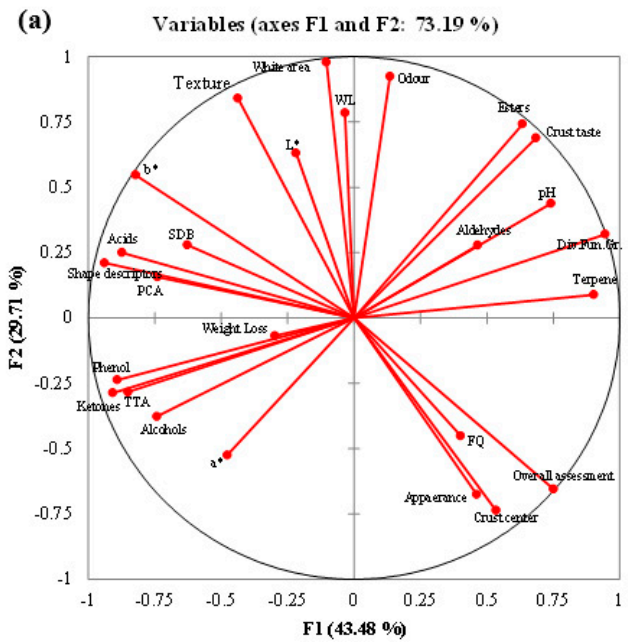

(b)

Observations (axes F1 and F2: $73.19 \%$ )

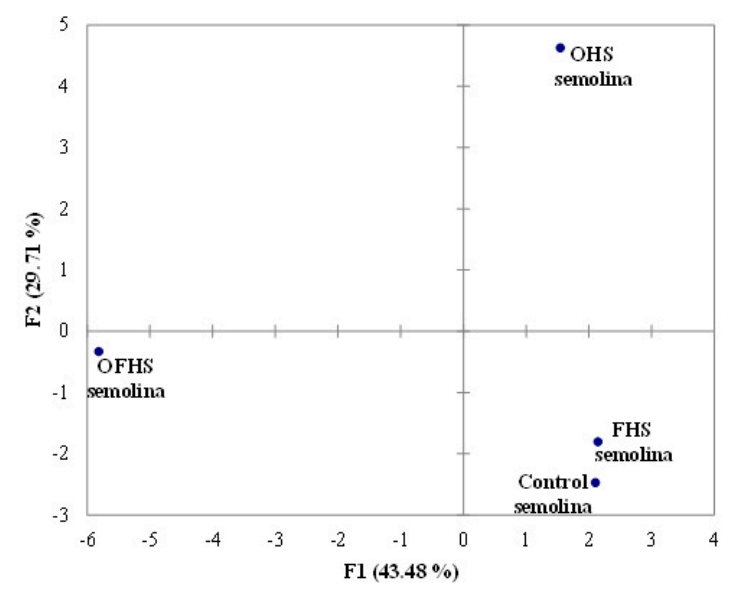

Figure 7. Loading plot (a) and score plot (b) resulting from principal component analysis on 26 variable groups determined on fermented pizza doughs, baked unseasoned pizzas, and final seasoned products. Abbreviations: FQ—fermentation quotient; PCA—plate count agar; WL-Wallerstein laboratory medium; SDB — sourdough bacteria medium; TTA—-total titratable acidity; OHS—obligate heterofermentative lactobacilli; FHS—facultatively heterofermentative lactobacilli; OFHS_obligate heterofermentative lactobacilli. 


\section{Conclusions}

Based on microbiological, chemical, physical, and sensory parameters, the differences/variabilities among the trials evaluated by multivariate relationships indicated that the pizzas obtained with different inocula were quite distant. In particular, the control trial clustered close to the trial carried out with FHS LAB, indicating that the role of these LAB species is of paramount importance during sourdough pizza propagation. In general, the monitoring of the acidification process indicated the kinetics of evolution of pH and TTA, as well as a LAB development comparable among all of the trials. The highest level of lactic acid was determined for the OFHS trial. The fermentation quotient of the FHS trial was particularly higher than that of the other trials, because of the low acetic acid generation. The most dominant strains were L. sanfranciscensis PON 100336, L. brevis 200571, and L. plantarum PON 100148. Several important differences were found for several physical attributes, and the multivariate statistical approach found marked differences among the trials. In general, the enhancement of the desired flavor attributes, especially the acidic and salty notes, were observed in the presence of the obligate heterofermentative LAB. The final products showing the best overall assessment by the judges were obtained from the control sourdough and the FHS inocula. Thus, the traditional regional habit of using semolina, especially from old T. turgidum ssp. durum genotypes, for pizza production is directly related to the fermentation carried out by facultative heterofermentative LAB species.

Author Contributions: Conceptualization, A.A. and L.S.; Methodology, A.A., G.R. and R.G.; Software, N.F.; Validation, N.F. and G.M.; Formal Analysis, A.A., O.C. and N.P.; Investigation, A.A. and R.G.; Data Curation, A.A., O.C. and R.G.; Writing-Original Draft Preparation, L.S.; Writing-Review \& Editing, A.A. and L.S.; Supervision, G.M. and L.S.; Project Administration, L.S.

Funding: This work was financially supported by the Project for Industrial Research and Training, PON01_02249, "Application of molecular biotechnologies and pro-technological microorganisms for the characterisation and valorisation of dairy and bakery chains of typical products", of the Italian Ministry of Education, University, and Research (CUP: B11C11000430005).

Acknowledgments: The authors are grateful to the staff of the pizzeria, "Frank's PIZZA" (Carini, Italy), and "Le Grotte del Kemonia" (Palermo, Italy), for their support during the pizza dough production and baking.

Conflicts of Interest: The authors declare no conflicts of interest.

\section{References}

1. Caporaso, N.; Panariello, V.; Sacchi, R. The “True" Neapolitan pizza: Assessing the influence of extra virgin olive oil on pizza volatile compounds and lipid oxidation. J. Culin. Sci. Food Technol. 2015, 13, $29-48$. [CrossRef]

2. Chavan, R.S.; Chavan, S.R. Sourdough Technology-A Traditional Way for Wholesome Foods: A Review. Compr. Rev. Food Sci. Food Saf. 2011, 10, 170-183. [CrossRef]

3. Corsetti, A.; Settanni, L. Lactobacilli in sourdough fermentation: A review. Food Res. Int. 2007, 40, 539-558. [CrossRef]

4. Corsetti, A.; Settanni, L.; Van Sinderen, D.; Felis, G.E.; Dellaglio, F.; Gobbetti, M. Lactobacillus rossii sp. nov. isolated from wheat sourdough. Int. J. Syst. Evol. Microbiol. 2005, 55, 35-40. [CrossRef] [PubMed]

5. Vera, A.; Rigobello, V.; Demarigny, Y. Comparative study of culture media used for sourdough lactobacilli. Food Microbiol. 2009, 26, 728-733. [CrossRef] [PubMed]

6. Hammes, W.P.; Vogel, R.F. The genus Lactobacillus. In The Genera of Lactic Acid Bacteria; Wood, B.J.B., Holzapfel, W.H., Eds.; Blackie Academic \& Professional: London, UK, 1995; pp. 19-54.

7. Coppola, S.; Pepe, O.; Masi, P.; Sepe, M. Characterization of leavened doughs for pizza in Naples. Adv. Food Sci. 1996, 18, 160-162.

8. Coppola, S.; Pepe, O.; Mauriello, G. Effect of leavening microflora on pizza dough properties. J. Appl. Microbiol. 1998, 85, 891-897. [CrossRef] [PubMed]

9. Salovaara, H. Lactic acid bacteria in cereal-based products. In Lactic Acid Bacteria Microbiology and Functional Aspects; Salminen, S., von Wright, A., Eds.; Marcel Dekker: New York, NY, USA, 1988; pp. 115-138. 
10. Corsetti, A.; De Angelis, M.; Dellaglio, F.; Paparella, A.; Fox, P.F.; Settanni, L.; Gobbetti, M. Characterization of sourdough lactic acid bacteria based on genotypic and cell-wall protein analyses. J. Appl. Microbiol. 2003, 94, 641-654. [CrossRef] [PubMed]

11. Axelsson, L. Lactic acid bacteria: Classification and physiology. In Lactic Acid Bacteria Microbiology and Functional Aspects; Salminen, S., von Wright, A., Eds.; Marcel Dekker: New York, NY, USA, 1998; pp. 1-72.

12. Corona, O.; Alfonzo, A.; Ventimiglia, G.; Nasca, A.; Francesca, N.; Martorana, A.; Settanni, L. Industrial application of selected lactic acid bacteria isolated from local semolinas for typical sourdough bread production. Food Microbiol. 2016, 59, 43-56. [CrossRef] [PubMed]

13. Gobbetti, M.; Simonetti, M.S.; Corsetti, A.; Santinelli, F.; Rossi, J.; Damiani, P. Volatile compound and organic acid production by mixed wheat sour dough starters: Influence of fermentation parameters and dynamics during baking. Food Microbiol. 1995, 12, 497-507. [CrossRef]

14. Alfonzo, A.; Ventimiglia, G.; Corona, O.; Di Gerlando, R.; Gaglio, R.; Francesca, N.; Settanni, L. Diversity and technological potential of lactic acid bacteria of wheat flours. Food Microbiol. 2013, 36, 343-354. [CrossRef] [PubMed]

15. Alfonzo, A.; Miceli, C.; Nasca, A.; Franciosi, E.; Ventimiglia, G.; Di Gerlando, R.; Settanni, L. Monitoring of wheat lactic acid bacteria from the field until the first step of dough fermentation. Food Microbiol. 2017, 62, 256-269. [CrossRef] [PubMed]

16. Ventimiglia, G.; Alfonzo, A.; Galluzzo, P.; Corona, O.; Francesca, N.; Caracappa, S.; Settanni, L. Codominance of Lactobacillus plantarum and obligate heterofermentative lactic acid bacteria during sourdough fermentation. Food Microbiol. 2015, 51, 57-68. [CrossRef] [PubMed]

17. Kline, L.; Sugihara, T.F. Microorganisms of the San Francisco sourdough bread process. II. Isolation and characterization of un described bacterial species responsible for the souring activity. Appl. Microbiol. 1971, 21, 459-465. [PubMed]

18. Settanni, L.; Ventimiglia, G.; Alfonzo, A.; Corona, O.; Miceli, A.; Moschetti, G. An integrated technological approach to the selection of lactic acid bacteria of flour origin for sourdough production. Food Res. Int. 2013, 54, 1569-1578. [CrossRef]

19. Alfonzo, A.; Urso, V.; Corona, O.; Francesca, N.; Amato, G.; Settanni, L.; Di Miceli, G. Development of a method for the direct fermentation of semolina by selected sourdough lactic acid bacteria. Int. J. Food Microbiol. 2016, 239, 65-78. [CrossRef] [PubMed]

20. Cruciata, M.; Gaglio, R.; Scatassa, M.L.; Sala, G.; Cardamone, C.; Palmeri, M.; Settanni, L. Formation and characterization of early bacterial biofilms on different wood typologies applied in dairy production. Appl. Environ. Microbiol. 2018, 84, e02107-e02117. [CrossRef] [PubMed]

21. Gaglio, R.; Francesca, N.; Di Gerlando, R.; Mahony, J.; DeMartino, S.; Stucchi, C.; Settanni, L. Enteric bacteria of food ice and their survival in alcoholic beverages and soft drinks. Food Microbiol. 2017, 67, 17-22. [CrossRef] [PubMed]

22. Bernklau, I.; Neußer, C.; Moroni, A.V.; Gysler, C.; Spagnolello, A.; Chung, W.; Becker, T. Structural, textural and sensory impact of sodium reduction on long fermented pizza. Food Chem. 2017, 234, 398-407. [CrossRef] [PubMed]

23. Ferreira, T.; Rasband, W. ImageJ User Guide IJ1.46r. 2012. Available online: https://imagej.nih.gov/ij/docs / guide/user-guide.pdf/ (accessed on 12 December 2017).

24. Comendador, F.J.; Cavella, S.; Di Monaco, R.; Dinnella, C.; Moneta, E.; Monteleone, E.; Sinesio, F. Il pane e altri prodotti da forno. In Atlante Sensoriale dei Prodotti Alimentari; Societa Italiana di Scienze Sensoriali, Ed.; Tecniche Nuove: Milano, Italy, 2012; pp. 156-176.

25. Martins, Z.E.; Erben, M.; Gallardo, A.E.; Silva, R.; Barbosa, I.; Pinho, O.; Ferreira, I.M. Effect of spent yeast fortification on physical parameters, volatiles and sensorial characteristics of home-made bread. Int. J. Food Sci. Technol. 2015, 50, 1855-1863. [CrossRef]

26. Klikocka, H.; Tatarczak, A. The use of cluster analysis to evaluate yield and yield components of spring barley in a two-variable field experiment. Int. J. Agric. Stat. Sci. 2015, 11, 35-42.

27. Dillon, W.R.; Goldstein, M. Multivariate Analysis. Methods and Applications; John Wiley and Sons: New York, NY, USA, 1984.

28. Mazzei, P.; Francesca, N.; Moschetti, G.; Piccolo, A. NMR spectroscopy evaluation of direct relationship between soils and molecular composition of red wines from Aglianico grapes. Anal. Chim. Acta 2010, 673, 167-172. [CrossRef] [PubMed] 
29. Jolliffe, I.T. Principal Component Analysis; Springer: New York, NY, USA, 1986.

30. Yi, L.; Dong, N.; Liu, S.; Yi, Z.; Zhang, Y. Chemical features of Pericarpium Citri Reticulatae and Pericarpium Citri Reticulatae Viride revealed by GC-MS metabolomics analysis. Food Chem. 2015, 186, 192-199. [CrossRef] [PubMed]

31. Spicher, G. Baked goods. In Biotechnology; Rehm, H.J., Reed, G., Eds.; Verlag Chemie: Weinheim, Germany, 1983; pp. 1-80.

32. Minervini, F.; Di Cagno, R.; Lattanzi, A.; De Angelis, M.; Antonielli, L.; Cardinali, G.; Gobbetti, M. Lactic acid bacterium and yeast microbiotas of 19 sourdoughs used for traditional/typical Italian breads: Interactions between ingredients and microbial species diversity. Appl. Environ. Microbiol. 2012, 78, 1251-1264. [CrossRef] [PubMed]

33. Gänzle, M.G.; Ehmann, M.; Hammes, W.P. Modeling of growth of Lactobacillus sanfranciscensis and Candida milleri in response to process parameters of sourdough fermentation. Appl. Environ. Microbiol. 1998, 64, 2616-2623. [PubMed]

34. Ottogalli, G.; Galli, A.; Foschino, R. Italian bakery products obtained with sourdough: Characterization of the typical microflora. Adv. Food Sci. 1996, 18, 131-144.

35. Lhomme, E.; Orain, S.; Courcoux, P.; Onno, B.; Dousset, X. The predominance of Lactobacillus sanfranciscensis in French organic sourdoughs and its impact on related bread characteristics. Int. J. Food Microbiol. 2015, 213, 40-48. [CrossRef] [PubMed]

36. Valmorri, S.; Settanni, L.; Suzzi, G.; Gardini, F.; Vernocchi, P.; Corsetti, A. Application of a novel polyphasic approach to study the lactobacilli composition of sourdoughs from the Abruzzo region (central Italy). Lett. Appl. Microbiol. 2006, 43, 343-349. [CrossRef] [PubMed]

37. Messens, W.; De Vuyst, L. Inhibitory substances produced by Lactobacilli isolated from sourdoughs-A review. Int. J. Food Microbiol. 2002, 72, 31-43. [CrossRef]

38. De Vuyst, L.; Neysens, P. The sourdough microflora: Biodiversity and metabolic interactions. Trends Food Sci. Technol. 2005, 16, 43-56. [CrossRef]

39. Birch, A.N.; Petersen, M.A.; Hansen, Å.S. Review: Aroma of wheat bread crumb. Cereal Chem. J. 2013, 91, 105-114. [CrossRef]

40. Purlis, E.; Salvadori, V.O. Modelling the browning of bread during baking. Food Res. Int. 2009, 42, 865-870. [CrossRef]

41. Hansen, A.; Schieberle, P. Generation of aroma compounds during sourdough fermentation: Applied and fundamental aspects. Trends Food Sci. Technol. 2005, 16, 85-94. [CrossRef]

42. Salim-ur-Rehman Paterson, A.; Piggott, J.R. Flavour in sourdough breads: A review. Trends Food Sci. Technol. 2006, 17, 557-566. [CrossRef]

43. Molard, R.; Nago, M.C.; Drapron, R. Influence of breadmaking method on French bread flavour. Baker's Dig. 1979, 53, 34-38.

44. Pico, J.; Bernal, J.; Gómez, M. Wheat bread aroma compounds in crumb and crust: A review. Food Res. Int. 2015, 75, 200-215. [CrossRef] [PubMed]

45. Mildner-Szkudlarz, S.; Zawirska-Wojtasiak, R.; Szwengiel, A.; Pacyński, M. Use of grape by-product as a source of dietary fibre and phenolic compounds in sourdough mixed rye bread. Int. J. Food Sci. Technol. 2011, 46, 1485-1493. [CrossRef]

46. Glicerina, V.; Balestra, F.; Capozzi, F.; Dalla Rosa, M.; Romani, S. Influence of the addition of soy product and wheat fiber on rheological, textural, and other quality characteristics of pizza. J. Texture Stud. 2017. [CrossRef] [PubMed]

47. Dziedzic, K.; Szwengiel, A.; Górecka, D.; Rudzińska, M.; Korczak, J.; Walkowiak, J. The effect of processing on the phytosterol content in buckwheat groats and by-products. J. Cereal Sci. 2016, 69, 25-31. [CrossRef]

(C) 2018 by the authors. Licensee MDPI, Basel, Switzerland. This article is an open access article distributed under the terms and conditions of the Creative Commons Attribution (CC BY) license (http://creativecommons.org/licenses/by/4.0/). 